\title{
A Supply-Demand Model on Allocation of Water Resources

\author{
Tian-hao $\mathrm{WU}^{1, \mathrm{a}^{*}}$ \\ ${ }^{1}$ North China Electric Power University, Baoding, China \\ a6653196@qq.com
}

Keywords: Water scarcity, Supply-Demand model, Water transfer, Intervention

\begin{abstract}
Two basic models are constructed in this paper to study water scarcity. The first model demonstrates an intuitive association between water supply and demand. The second model illustrates how to achieve the optimal allocation of water resources through our intervention. Taking Southwest America for example, this paper analyses the water scarcity condition by using supply-demand model and then gives qualitative analysis of inter basin water transfer. Conclusion shows our model has positive effect on alleviating water resources scarcity and making the distribution of water resources more reasonable. In the end, this paper analyses some strengths and weaknesses of our model to make the model more practice and applicable.
\end{abstract}

\section{Introduction}

With the rapid development of economy and population growth, the water scarcity gradually becomes a severe obstacle of the whole world. Take America for example, the severe drought lasting from year 2007 has affected more than half of the population in California. The Colorado River has even lost plenty of its water sources in the west of the Rocky Mountains [USGS,2010]. So it is crucial to do the researches on how to reduce the water pressure.

In recent years, large amount of researches on water issues have been conducted by scientists. With the globalization continues to develop, we not only care about in what situations we are but also show our concerns on how other's lives are. In a word, there are already some achievements on analyzing the different types of water scarcity in both the time and space dimensions. Among them, a famous model is illustrated by Joao Marques taking the water issues into a broader circumstance [10]. In the following papers, a significant model is given out by the author Declan Conway and Emma Archer van Garderen who mainly focus on how the water scarcity happens and the mechanism of the water-food-energy nexus [11]. Then the ecology scientists continue to conduct a further study on the links between the detailed economic items and the water shortage. The latest studies reveal that both the causes for water scarcity and the scarcity influences on other aspects all have inner relations with the social, ecological and economic drivers. And these relationships can be quantitatively described by the multi-objective programming and the neural networks [12].

However, there still lacks a clear definition and comprehension on the water availability of a region. What's more, some of the current existing models are too complicated to take into actual use which definitely leads to the vague work in further analysis of the effects on local area. In short, when turning back to the problem itself, that is, how to measure water availability and what to do to solve scarcity problems. Figure 1 below reflects our main thinking method. 


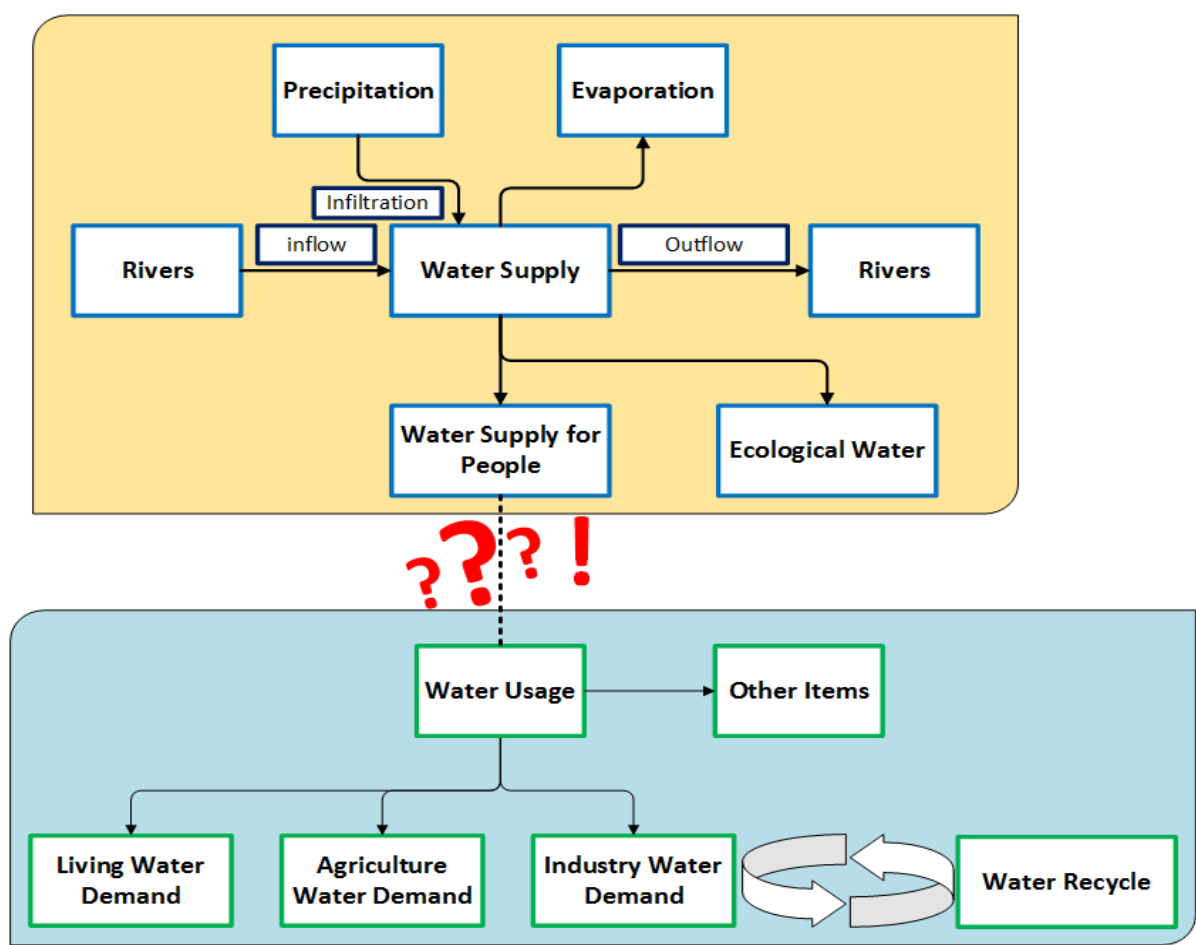

Figure 1 Flow diagram of solution work

\section{Establishment of the Supply-Demand Model}

In order to understand the abstract meaning of water capability, we create the Supply-Demand model. In the Cartesian right-angle coordinate system, the horizontal axis stands for supply while the vertical axis stands for demand. The function between the two variables can therefore be simulated. Besides, the straight line : $y=x$ which evenly divides the first quadrant into I and II parts is displayed to stand for the balance of supply and demand. The relationship is shown in the following figure:

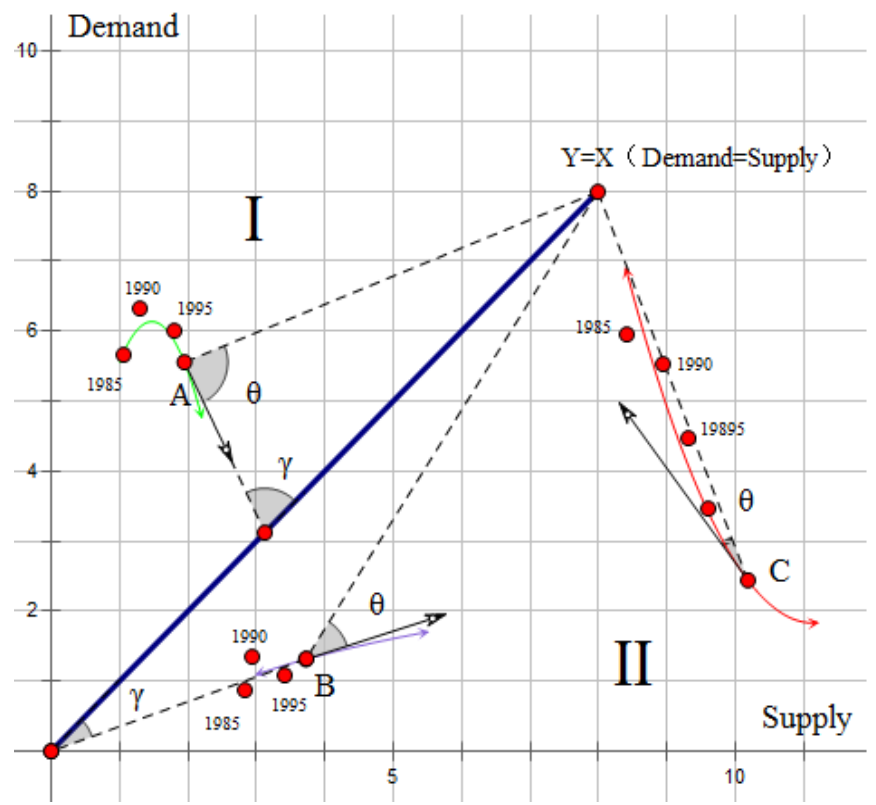

Figure 2 Supply-Demand model

Viewing from the figure, the function curve which falls into region I means that along this path the demand is surpassing the supply, while on the contrary, it represents that the supply is surpassing the demand. Here $\kappa$ is defined as the reflection index. When $\kappa=1$, the situation is the idealist. And the relationship is as follows: 


$$
\kappa=\frac{W_{\text {demand }}}{W_{\text {sup ply }}}
$$

Apparently, this model is used to mainly reflect the current situation. However, to a certain extent, it can also predict the future state under the influence of various dynamic factors . As is shown in the figure, the trend in the future can be expressed by the slope of the curve. Take the green curve for example(see the figure), when the tangent slope is greater than zero, a conclusion can be drawn that over a period of time the demand will be higher than supply, which suggests some interventions should be conducted to balance the two variables or there will be water scarcity. By analyzing the value of $\gamma$, the deviation degree between the fact and ideal situation can easily be understood. For convenience, the calculation for the value of $\gamma$ is transformed into this format:

$$
\tan \gamma=\frac{\kappa_{1}-\kappa_{0}}{1+\kappa_{1} \kappa_{0}}
$$

When the tangent slope approaches to 1 , we can say that the situation comes to a stable trend. And in the next section, the detailed process of model calculating will be discussed.

\section{Analysis of Water Scarcity Degree___Take Southwest America for example}

As the water scarcity map shows, the Southwest America is facing drought and water scarcity crisis $[1,2]$. So we choose this region as our research object to text our model. The whole area consists of California, Nevada, Colorado, Utah, New Mexico and Arizona. The major work is shown below.

Based on the Supply-Demand model, we figure out the value of $\kappa$ respectively by analyzing collected data of each subarea. The result is shown in the Table 1.

Table 1 Matching degree of supply and demand of six subareas

\begin{tabular}{ccccccc}
\hline Subarea & California & Nevada & Colorado & Utah & New Mexico & Arizona \\
\hline$\kappa$ & 2.238 & 0.864 & 1.447 & 0.776 & 1.734 & 1.974 \\
\hline
\end{tabular}

From the table above, we can have a rough understand that California has suffered the most serious shortage dilemma. So California has promulgated its first Water Limit Order to restrict the water usage. For New Mexico and Colorado, shortage phenomenon has also appeared. For other two states, they will experience a period of stability [3].

Then we define a weighted index $\square \square \square$ to reflect the ration of the actual water supply and the ideal water demand. By making using of Supply-Demand model, Figure 3 can be drawn to reflect the balance between water supply and demand in Southwest America at present.
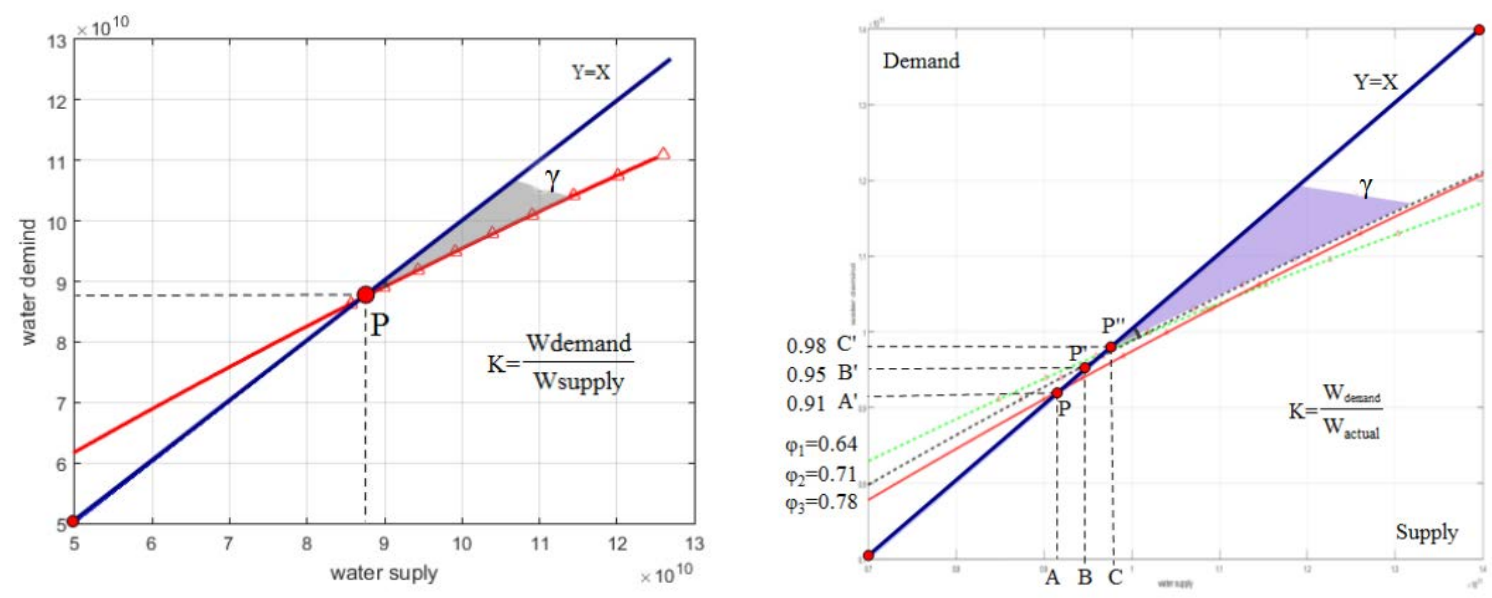

Figure 3 The supply and demand relation before and after model updating 
As is shown in the figure above, when $\varphi=0.71$, the equal points $\kappa$ of the whole area will reach the value 0.95, then we can predict by genetic algorithm that after year 2024, people in Southwest America will face the severe water shortage condition. To some degree, the less the values of curve is, the larger $\tan \gamma$ will be, which means the degree of deviation between the ideal and actual situation $[4,5]$.

\section{Inter-basin water transfer intervention fixed according to supply-demand model}

Comparing the data we get from Table 1, different places is facing varying degrees of water shortage. California is faced with severe water scarcity while the water supply will not meet the demand in Arizona and New Mexico. Fortunately, the water resources are relatively abundant in Utah which can be set as a water-supply area for other places. So the water intervention is based on the former analysis. The whole plan includes the Cross-Regional Water Transfer Project and new establishment of dams. However, all of the water plans have to take the actual terrain and climate factors into consideration. The following Figure 4 roughly shows our plan [6].

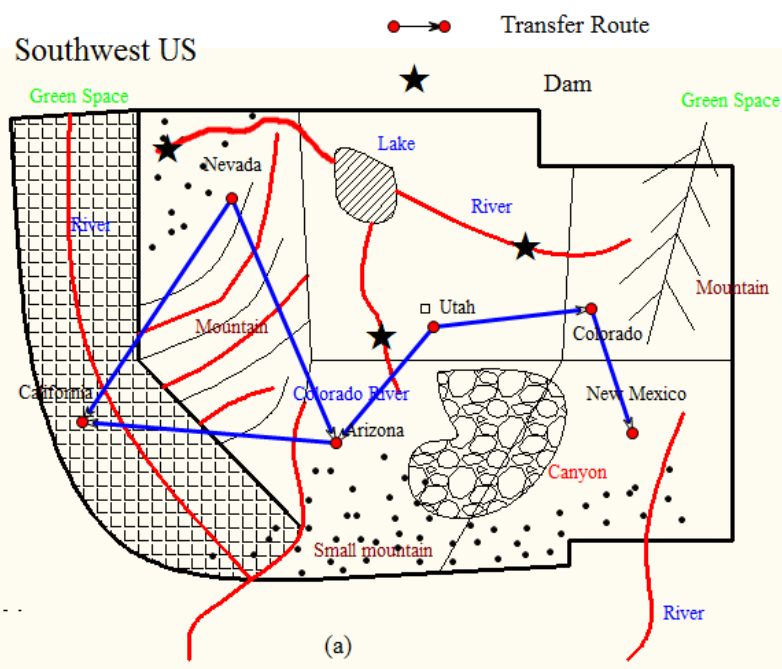

(a)

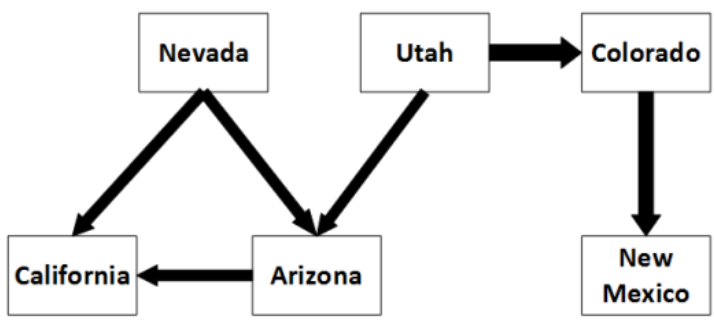

(b)

Figure 4 Intervention plan proposed to relieve water scarcity

(a) Topographic map and water transfer routes

(b) Detailed water transfer routes

Since California is faced with water scarcity. And in the surrounding area, Nevada has relatively abundant water resources while Arizona is in lack of water. According to the local geography, the Colorado River flows exactly along the border of the former states, so the water can be transferred from it to both California and Arizona(shown as the two blue lines connecting Nevada, Arizona and California). The other part of the plan transfers water from Nevada to California through the nature river running in the north of Nevada. What's more, Utah can transfer water to both Arizona and Colorado. Meanwhile, considering that Colorado is also in lack of water, we can transfer more water from Utah to Colorado with fewer transmission from Colorado to New Mexico [7].

According to the intervention implemented before, we acquire the information that there has been three major dams in Southwest America already, which is, the Glen Canyon Dam located near the Sierra in Nevada, Hoover Dam located at the junction of Nevada and Arizona together with the Monticello Dam located in California. Considering the terrain factors, three new dams are established to help transfer water [8]. The dams are respectively located in Nevada, at the junction of Utah and Arizona with the last location at the junction of Utah and Colorado. Then with the assistance of these dams, the water transference can be more easily achieved. Finally, given that there may be some influence of El Nino phenomenon and La Nina phenomenon, the internal water transference in California isn't in our consideration [9]. 


\section{Conclusion}

During the whole process, we establish two main models in total. The first model demonstrates the association between water supply and demand. The second model illustrates ways to achieve the optimal allocation of water resources. In addition, we make intervention plan for Southwest American and discuss its overall impact on surrounding areas. During the model, we take both environmental and social influence into consideration when set up our models and text our model based on quantitative analysis of dynamic factors such as population growth, which makes our models more conformed to reality. Later we may need to consider some detailed demands to make our model to be suitable for more other regions. At last, based on analysis, we draw a conclusion that our model is robust and it is promising to be adopted to practical usage.

\section{References}

[1] M.E. Gilpin, F.J. Ayala, Global models of growth and competition, Proc. Natl. Acad. Sci. U.S.A. 70 (1973) 3590-3593.

[2] The water scarcity map:http://www.unep.org/dewa/vitalwater/jpg/0222-waterstress-overuse-EN.jpg

[3] Christensen NS, Wood AW, Voisin N, Lettenmaier DP, Palmer RN (2004) The effects of climate change on the hydrology and water resources of the Colorado River Basin. Clim Change 62:337-363.

[4] California State Water Resources Control Board, 2013, Once-through cooling policy protects marine life and insures electric grid reliability, accessed July 7, 2014: 2-3.

[5] Water overview on Southwest America:

http://nca2014.globalchange.gov/report/regions/southwest

[6] Barnett, T. P., D. W. Pierce, H. G. Hidalgo, C. Bonfils, B. D. Santer, T. Das, G. Bala, A. W. Wood, T. Nozawa, A. A. Mirin, D. R. Cayan, and M. D. Dettinger, 2008: Human-induced changes in the hydrology of the western United States. Science, 319, 1080-1083.

[7] Black storm in America history: https://en.wikipedia.org/wiki/Black_Sunday_(storm)

[8] Water usage data: http://water.usgs.gov/watuse/50years.html

[9]Xinyi Xu, Hao Wang, Hong Gan, et al: Macro-economic water resources planning theory and method in North China. Yellow River Water Conservancy Press, Zhengzhou (1997).

[10] Joao Marques a, Maria Cunha, Dragan A. Savic, et al: Multi-objective optimization of water distribution systems based on a real options approach 14 July 2014.

[11] Declan Conway, Emma Archer van Garderen, Delphine Deryng, Steve Dorling, Tobias Krueger, Willem Landman, Bruce Lankford, Karen Lebek, Tim Osborn, Claudia Ringler, James Thurlow, Tingju Zhu and Carole Dalin, et al: Climate and southern Africa's water-energy-food nexus 18 June 2015.

[12] M. Habibi Davijani, M.E. Banihabib, A. Nadjafzadeh Anvar, S.R. Hashemi, et al: Optimization model for the allocation of water resources based on the maximization of employment in the agriculture and industry sectors. 